\title{
Turmeric extract decreased frequency of polychromatic erythrocytes micronuclei induced by iodine-131
}

\author{
M. Jadidi ${ }^{*}$, A.A. Taherian², M. Mahdinejad ${ }^{1}$, P. Hejazi ${ }^{1}$ \\ ${ }^{1}$ Department of Medical Physics, School of Medicine, Semnan University of Medical Sciences, Semnan, Iran \\ ${ }^{2}$ Research Center and Department of Physiology, School of Medicine, Semnan University of Medical Sciences,
} Semnan, Iran

\section{- Original article}

\author{
*Corresponding author: \\ Dr. Majid Jadidi, \\ Fax: +982333654209 \\ E-mail: jadidim@semums.ac.ir \\ Revised: Sept. 2015 \\ Accepted: Oct. 2015 \\ Int. J. Radiat. Res., January 2016; \\ 14(1): 47-51 \\ DOI: 10.18869 /acadpub.ijrr.14.1.47
}

\begin{abstract}
Background: lonizing radiation irradiated from iodine-131 can induce DNA damage and cell death. The cellular DNA damage is the cause of mutation and cancer. The micronucleus assay in polychromatic erythrocytes was applied to assess the radio-protective effect of Turmeric extract on genotoxic potential of iodine therapy. Materials and Methods: Thirty six male albino rats were randomly divided in six groups. A single dose (200 or $500 \mathrm{mg} / \mathrm{kg}$ ) of Turmeric extract was injected to the rats $30 \mathrm{~min}$ before iodine therapy. lodine-131 (5.55 $\mathrm{MBq}$ ) was administrated intra peritoneal to the experimental animals. The percentage of micronuclei in PCE, NCE and ratio of PCE / (PCE + NCE) was determined $48 \mathrm{~h}$ after iodine injection for each experimental group to assess iodine-131 radiation effects with or without Turmeric extract. Results: lodine therapy showed a significant increase in the number of micronucleus formation. The animals treated with different doses of Turmeric extract + iodine showed a significant reduction in the frequency of micronucleus compared to the animals treated with iodine-131 alone. Both doses of Turmeric extract had the same effect when injected 30 min prior to iodine therapy. Conclusion: Our results indicate protective effect of Turmeric extract against genetic damages induced by iodine-131 administration.
\end{abstract}

Keywords: Turmeric, iodine-131, micronucleus.

\section{INTRODUCTION}

Iodine-131 (131I) was successfully used in the treatment of hyperthyroidism and differentiated thyroid diseases (1). 131I also cause side effects in many organs, glands and increased risk of second malignancy (2). 131I emits Beta and Gamma ionizing radiations thus cause biologic effects $(3,4)$. Radiation of ${ }^{131}$ I generates reactive oxygen species (ROS) in the cells. These free radicals can damage macromolecules such as DNA. The cellular DNA damage is the cause of mutation and cancer (5).

Development of a suitable radio-protector with minimum toxicity that could be used in clinical conditions, is an obligation (6), consequently recent studies focused on natural radio-protectors, regarding to less toxicity and side effects. There are many plant derived natural antioxidants that interfere with free radicals before they can damage the body. Antioxidants work in several ways, either by reducing the energy of the free radicals, stopping the free radicals from forming in the first place, or interrupting an oxidizing chain reaction and, thus, minimizing the damage this causes (7).

Curcuma longa (family Zingiberaceae), known as Haldi in India and Turmeric in English, has demonstrated a wide spectrum of therapeutic effects such as anti inflammatory, antioxidant, anti mutagenic and antitumor ${ }^{(8)}$.

Curcumin, a yellow colored phenolic pigment, is the most important fraction which is responsible for the biological activities of 
turmeric (9). No acute toxicity in mice was observed on administration of Turmeric powder with dose as high as $10 \mathrm{~g} / \mathrm{kgbw}(10)$. Protective action for normal cells and sensitizing effect on malignant cells would make it an ideal adjuvant agent for patients undergoing radiotherapy for cancer treatment (11). Therefore, in-vivo radioprotective activity of Turmeric extract was investigated by using ${ }^{131}$ I as a damaging agent. The aims of the present study, carried out in rats receiving therapeutic dose of ${ }^{131} \mathrm{I}$, were (1) to evaluate the micronuclei appearance in bone marrow cells after 131I therapy. (2) To ascertain the possibility for appearance of micronuclei in the non-irradiated rats were treated with Turmeric extract, and (3) to find out any reduction in the frequency of micronuclei in irradiated rats were pre-treated with a single dose of Turmeric extract.

\section{MATERIALS AND METHODS}

\section{Animals}

Thirty six male albino rats $(\geq 250$ gr) were obtained from the breeding colony of Semnan University of Medical Sciences, Semnan, Iran. They were housed six per cage randomly, maintained at constant temperature on a standard 12:12 h light/dark cycle, standard mouse pellets and water ad libitum. Rats were injected intra peritoneal for all experiments. All procedures were conducted in agreement with the National Institutes of Health Guide for care and use of laboratory animals. Six rats were used for each treatment group.

\section{Chemicals and treatment}

The dried rhizome of Turmeric was purchased from local market and were identified, classified and extracted, in the Applied Scientific educational center of Jihad-e Agriculture of Semnan. The voucher specimen (No. 93-11) was preserved and deposited in herbal library of research center of medicinal plants (Semnan University of medical sciences). For extraction, $200 \mathrm{gr}$ of dried rhizome were grinded and then extracted with $350 \mathrm{~mL} 80 \%$ methanol and $650 \mathrm{ml}$ water for 24 hrs in a continuous extraction by soxhlet apparatus. Extracted Turmeric used in a single dose (200 and $500 \mathrm{mg} / \mathrm{kg}$ ) (12) intraperitoneal injection by 26-gauge syringe $30 \mathrm{~min}$ before iodine therapy tests. The control animals received the same volume of normal saline. Six rats were used for each treatment group.

Dosage of iodine-131 was extrapolated from human dose $(40 \mathrm{mCi})$ that could be used for iodine therapy in clinical trial. According to rats weight, nearby $5.5 \mathrm{MBq}(150 \mu \mathrm{Ci}){ }^{131}$ I was injected with an insulin syringe intra peritoneal to the experimental animals.

\section{Micronucleus assay}

The animals were euthanized by cervical dislocation $48 \mathrm{~h}$ after iodine injection (13). The bone marrow from both femurs was flushed in the form of a fine suspension into a centrifuge tube containing fetal Bovine serum (FBS) (Gibco). The cells were dispersed by gentle pipetting and collected by centrifuge at 1000 rpm for $8 \mathrm{~min}$ at $4^{\circ} \mathrm{C}$. The cell pellet was resuspended in a drop of FBS and bone marrow smears were prepared. The slides were coded to avoid observer bias. After $24 \mathrm{~h}$ air-drying, the smears were stained with May-Grunwald/ Giemsa (Sigma). With this method polychromatic erythrocytes (PCEs) stain reddish-blue and normochromatic erythrocytes (NCEs) stain orange, while nuclear material is dark purple. For each animal, a total of 1000 PCEs were scored from prepared slides to determine the percentage of micronucleated polychromatic erythrocytes (MnPCEs), micronucleated normochromatic erythrocytes (MnNCEs) and ratio of PCE to (PCE + NCE). The ratio of PCE to (PCE + NCE) was determined for each experimental group to assess iodine radiation effects with or without Turmeric extract on chromosome aberrations (14). To diminish the bias of observer, some of slides were randomly scored by another witness.

\section{Statistical analysis}

Micronucleus data were analyzed using Student's t-test. Statistical analysis was performed using SPSS statistical software (16.0, USA); P values of $<0.05$ were considered to indicate statistical significance. All results were expressed as mean \pm SD for six animals in each group. 


\section{RESULTS}

Microscopic examination of PCEs showed that there were several MN formations in the control and Turmeric extract (TE) treated groups. The MN frequency of PCEs belonging to TE treated groups was fairly similar to control group. Iodine therapy showed a significant increase $(\mathrm{P}<0.0001)$ in the number of $\mathrm{MN}$ formation (figure. 1). The animals treated with different doses of $\mathrm{TE}+$ iodine showed a significant reduction $(\mathrm{P}<0.05)$ in the frequency of MN compared to the animals treated with ${ }^{131}$ I alone. Both doses of Turmeric extract (250 and $500 \mathrm{mg} / \mathrm{kg})$ had same effect $(\mathrm{P}<0.05)$, when injected $30 \mathrm{~min}$ prior to iodine therapy but, The total MnPCEs values were 9 and 36 fold less in the 250 and $500 \mathrm{mg} / \mathrm{kg}$ TE groups after being exposed to ${ }^{131}$ I, respectively, than those in the respective ${ }^{131}$ I alone. Pre-treatment of irradiated groups with TE caused significantly less damage and resulted in a much lower frequency of MnNCEs which reached about 3 and 7 fold less in the 250 and $500 \mathrm{mg} / \mathrm{kg} \mathrm{TE}+$ iodine groups, respectively, than those in ${ }^{131}$ I alone (figure. 2). With a further increase in the Turmeric dose to $500 \mathrm{mg} / \mathrm{kg}$, there was no increase effect of TE on the frequency of MnNCEs induced by iodine-irradiation $(\mathrm{P}>0.05)$.

As shown in figure. 3 , the ratio of PCE/PCE+NCE reduced significantly $(\mathrm{p} 0 .<001)$ after iodine therapy. Determination of ratio of PCE/PCE+NCE in the irradiated rats showed a cytotoxic effect of radiation on bone marrow proliferation. Treatment of rats with Turmeric extract blocked the radiation-induced decline in the PCE/PCE+NCE ratio and this increase in the PCE/PCE+NCE ratio in the TE + iodine groups was higher than that of the irradiated-alone group ( $0 .<05)$. Both doses were effective in significantly reducing $(\mathrm{p} 0 .<001)$ the frequency of PCE/PCE+NCE induced by ${ }^{131}$ I irradiation.

\section{DISCUSSION}

Micronuclei (MN) are the result of chromosome acentric fragments (clastogenic effect) or whole chromosomes that, through incomplete migration, have been excluded from the main core (aneugenic effect). It has been shown that the micronuclei frequency assay can be used as a valuable endpoint and is a sensitive method for assessment of genetic damage by toxic agents $(15,16) .131$ I acts as a genotoxic agent on living cells and can increase the DNA damages. We observed that 131I has genotoxic effects in rat polychromatic erythrocytes at a dose $5.55 \mathrm{MBq}(150 \mu \mathrm{Ci})$ and the number of micronuclei increases significantly after iodine therapy.

In this study, we showed, Turmeric extract (Curcuma longa) protects rat's bone marrow polychromatic erythrocytes against genotoxicity induced by iodine internal irradiation. Natural compounds, for instance flavonoids, may play a role in scavenging free radicals, such as hydroxyl, that is the result of gamma rays in cells. Ionizing radiation produce free radical and this radicals damage DNA and induces genotoxic effects and death in the cells (5). When an organism is exposed to ionizing radiation, many systems are affected with maximum effects over rapidly dividing cells like hematopoietic stem cells and mucosal epithelium and morbidity or mortality depends upon initial damage at cellular level that depends upon presence of oxygen, sulfhydril group and cellular protective enzymes like superoxide dismutase, catalase etc. (17).

However preservation at cellular level would depend primarily on prevention of genotoxicity at cellular level and this would imply that presence of cellular protective agents or a change in cellular milieu interior in favor of cell against radiation assault must be achieved before the exposure; so pretreatment design was preferred (11). In our study, Pretreatment with Turmeric extract had protection effect on irradiation hazardous. Turmeric extract have strong antioxidant activity, even at low dosage, and in different forms, like spice, traditional preparation or herbal medicine, can provide a significant protection against oxidative damage (18). Lethal dose of Turmeric extract is more than $1000 \mathrm{mg} / \mathrm{kg}$ (19), and in our experiment, both doses of Turmeric extract (250 and $500 \mathrm{mg} / \mathrm{kg}$ ) had same effect $(\mathrm{P}<0.05)$. The percentage of

Int. J. Radiat. Res., Vol. 14 No. 1, January 2016 
PCE/PCE+NCE ratio declined in iodine treatment rat, since this ratio gives an index of cell division, Turmeric extract protected rats against radiation induced decline in cell proliferation, as evidenced by the increased of PCE/PCE+NCE ratio; and it is possible that Turmeric extract protects bone marrow cells with its antioxidant activity. Protective action for normal cells and sensitizing effect on malignant cells would make it an ideal adjuvant agent for patients undergoing radiotherapy for cancer treatment (11). So far, the potential of Turmeric extract in radio-iodine therapy has not been demonstrated in patients. Subsequently, to find more effective and ideal dose we need more research.

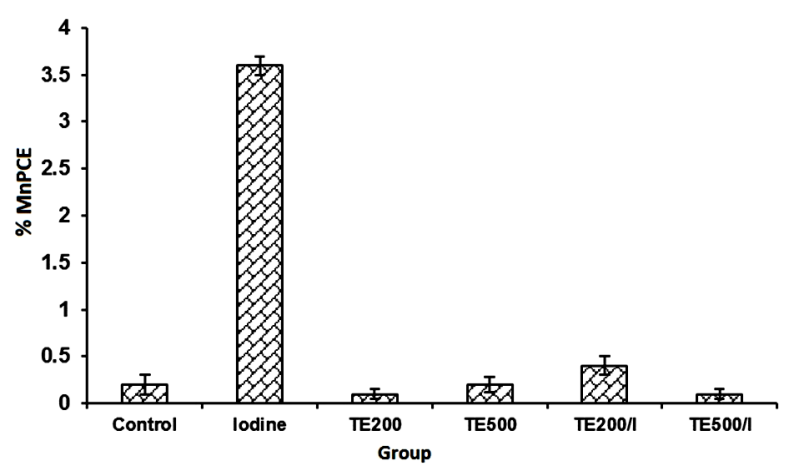

Figure 1.Effect of different dose of Turmeric extract on the frequency of MnPCE in the bone marrow of rat. (TE 200, Turmeric extract $200 \mathrm{mg} / \mathrm{Kg}$; TE 500, Turmeric extract $500 \mathrm{mg} / \mathrm{Kg}$; TE200/l, Turmeric extract $200 \mathrm{mg} / \mathrm{Kg}$ + lodine $5.55 \mathrm{MBq}$; TE500/l, Turmeric extract $500 \mathrm{mg} / \mathrm{Kg}+$ lodine $5.55 \mathrm{MBq}) .(* \mathrm{P}<0.05)$.

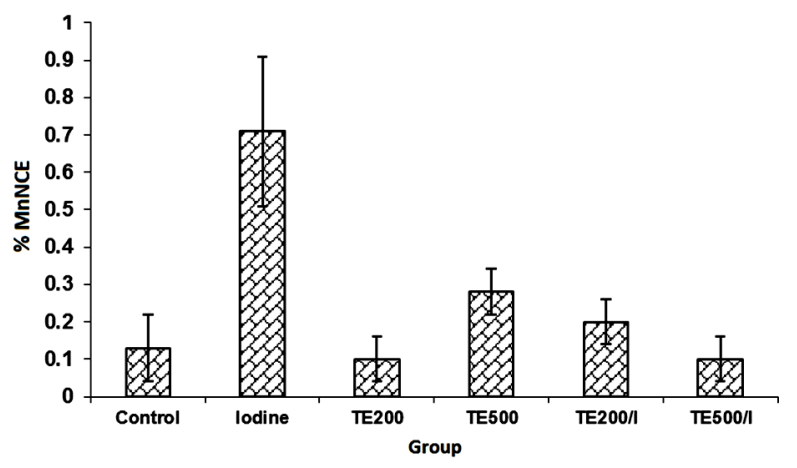

Figure 2.Effect of different dose of Turmeric extract on the frequency of MnNCE in the bone marrow of rat. (TE 200, Turmeric extract $200 \mathrm{mg} / \mathrm{Kg}$; TE 500, Turmeric extract $500 \mathrm{mg} / \mathrm{Kg}$; TE200/I, Turmeric extract $200 \mathrm{mg} / \mathrm{Kg}$ + lodine $5.55 \mathrm{MBq}$; TE500/I, Turmeric extract $500 \mathrm{mg} / \mathrm{Kg}+$ lodine $5.55 \mathrm{MBq})$. (* $\mathrm{P}<0.05)$.

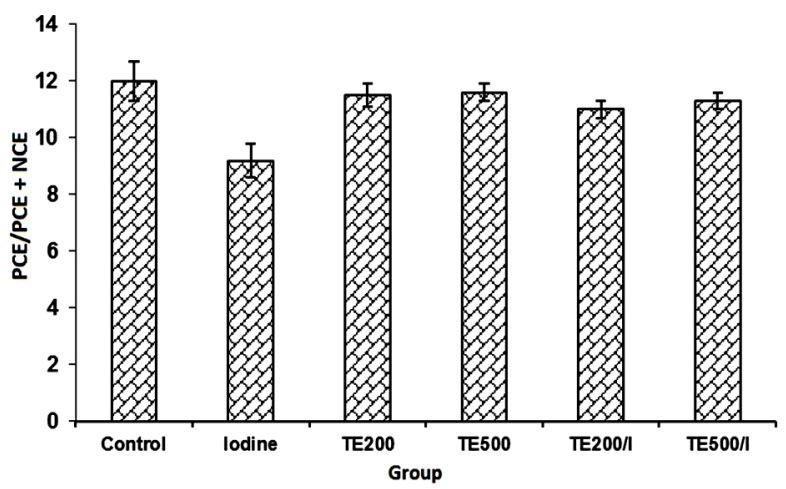

Figure 3. Effects of two doses of Turmeric extract on the radiation induced PCE/PCE+NCE ratio in the bone marrow of rat. (TE 200, Turmeric extract $200 \mathrm{mg} / \mathrm{Kg}$; TE 500, Turmeric extract $500 \mathrm{mg} / \mathrm{Kg}$; TE200/I, Turmeric extract $200 \mathrm{mg} / \mathrm{Kg}$ + lodine $5.55 \mathrm{MBq}$; TE500/I, Turmeric extract $500 \mathrm{mg} / \mathrm{Kg}+$ lodine $5.55 \mathrm{MBq})$. (* $\mathrm{P}<0.05$ ). 


\section{CONCLUSION}

Our results demonstrate that iodine therapy had a significant increase in the frequency of MN formation in PCEs and NCEs, while Turmeric extract gives pronounce protection to rat bone marrow against the clastogenic effects of iodine therapy. The possibility of reducing the genotoxic activity of radionuclide therapy by Turmeric extracts to be explored.

\section{ACKNOWLEDGMENT}

The authors gratefully acknowledge the technical assistance provided by Vahid Semnani. This work was supported by a Grant from the Semnan University of Medical Sciences (545).

\section{Conflicts of interest: none to declare.}

\section{REFERENCES}

1. Wyszomirska A (2012) lodine-131 for therapy of thyroid diseases. Physical and biological basis. Nucl Med Rev Cent East Eur, 15(2):120-3.

2. Van Nostrand D (2011) Sialoadenitis secondary to (131)I therapy for well-differentiated thyroid cancer. Oral Dis, 17 (2): 154-61.

3. Robbins RJ and Schlumberger MJ (2005) The evolving role of (131)I for the treatment of differentiated thyroid carcinoma. J Nucl Med, 46(1): 28S-37S.

4. Mumtaz M, Lin LS, Hui KC, Mohd Khir AS (2009) Radioiodine I-131 for the therapy of graves' disease. Malays J Med Sci, 16(1): 25-33.

5. Riley PA (1994) Free radicals in biology: oxidative stress and the effects of ionizing radiation. Int J Radiat Biol, 65 (1):27-33.

6. Citrin D, Cotrim AP, Hyodo F, Baum BJ, Krishna MC, Mitchell JB (2010) Radioprotectors and mitigators of radiation-induced normal tissue injury. Oncologist, 15(4): 360-71.
7. Agrawal A and Goyal P (2011) Radiation- induced hematological alterations and their inhibition by Aegle Marmelos fruit extract. Nucl Technol Rad, 26(3): 237-44.

8. Kohli K, Ali J, Ansari, MJ. Raheman Z (2004) Curcumin: A natural anti-inflammatory agent. Indian J Pharmacol, 37: 141-7.

9. Chattopadhyay I, Biswas K, Bandyopadhyay U, Banerjee RK (2004) Turmeric and curcumin: Biological actions and medicinal applications. Curr Sci, 87: 44-53.

10. Sittisomwong N, Leelasangluk V, Chivapat S (1990) Acute and subchronic toxicity of turmeric. Bull Dept Med Sci, 32 (8): 101-11.

11. Adhvaryu MR, Srivastav SP, Vaniawala SN, Reddy MN (2008) A comparative study of radioprotection by four Indian medicinal herbs against genotoxicity induced by sub -lethal gamma irradiation in Swiss albino mice. Iran J Radiat Res, 6(1):19-30.

12. Ullah AHM, Zaman S, Juhara F, Akter L, Tareq SM, Masum $\mathrm{EH}$, et al (2014) Evaluation of antinociceptive, in-vivo \& invitro anti-inflammatory activity of ethanolic extract of Curcuma zedoaria rhizome. BMC Complementary and Alternative Medicine, 14: 346.

13. D'Souza UJA, Zaina A, Raju S (2005) Genotoxic and cytotoxic effects in the bone marrow of rats exposed to a low dose of paraquat via the dermal route. Mutat Res, 581: 187-90.

14. Attia SM (2007) Chromosomal composition of micronuclei in mouse bone marrow treated with rifampicin and nicotine, analyzed by multicolor fluorescence in situ hybridization with pancentromeric DNA probe. Toxicology, 235(1-2): 112-8.

15. Fenech M (2000) The in-vitro micronucleus technique. Mutat Res, 455(1-2): 81-95.

16. Da Rocha CAM (2011) The micronucleus test in erythrocytes of Amphibian larvae as tool for Xenobiotic exposure risk assessment: A brief review and an example using lithobates catesbeianus exposed to copper sulphate. Middle-East Journal of Scientific Research, 8(1): 23-9.

17. Biakov VM and Stepanov SV (1997) Mechanism of primary radiobiologic action. Radiat Biol Radioecol, 37: 469-74.

18. Menghini L, Genovese S, Epifano F, Tirillini B, Ferrante C, Leporini L (2010) Antiproliferative, protective and antioxidant effects of artichoke, dandelion, turmeric and rosemary extracts and their formulation. Int $J$ Immunopathol Pharmacol, 23(2):601-10.

19. Govind P (2011) Active principles and median lethal dose of curcuma longa linn. International Research Journal of Pharmacy, 2(5): 239-41. 
